\title{
Neonatal Urinary Cotinine Correlates With Behavioral Alterations in Newborns Prenatally Exposed to Tobacco Smoke
}

\author{
GIUSEPPINA MANSI, FRANCESCO RAIMONDI, SIMONA PICHINI, LETIZIA CAPASSO, MICAELA SARNO, \\ PIERGIORGIO ZUCCARO, ROBERTA PACIFICI, ÓSCAR GARCIA-ALGAR, ALFONSO ROMANO, AND ROBERTO PALUDETTO

\begin{abstract}
Department of Pediatrics [G.M., F.R., L.C., MS, AR, R.Pal.], Division of Neonatology, University "Federico II", 80010 Naples, Italy; Drug Control and Evaluation Department [S.P., P.Z., R.Pac.], Istituto Superiore di Sanità, 00161 Rome, Italy; Service of Pediatrics [O.G.-A.], Unitat de Recerca Infància i Entorn (URIE), Hospital del Mar, Universitat Autònoma, E-08003 Barcelona, Spain
\end{abstract}

\begin{abstract}
Altered behavior due to prenatal smoke exposure was examined in 25 neonates born from smoking mothers who consumed at least 5 cigarettes/d during the entire gestation. Data were compared with 25 matched neonates born from nonsmoking mothers. Neonatal behavior was evaluated using the Brazelton Neonatal Behavioral Assessment Scale (BNBAS). Antenatal exposure to tobacco smoke at the end of the pregnancy was determined by measurement of urinary cotinine. Newborns from smoking mothers showed significant lower scores in various BNBAS items compared with neonates from nonsmoking mothers. A strong correlation was observed between infant irritability and urinary cotinine in newborns from smoker and nonsmoking mothers and with number of daily smoked cigarettes and maternal nicotine daily intake of infants exposed to active maternal smoking. Linear regression analysis showed that urinary cotinine was the best predictor of infant irritability $\left(r^{2}=0.727\right)$. The latter was also associated to the neonate's low level of attention and poor response to inanimate auditory stimuli. Among infants from nonsmoking mothers, paternal smoking significantly correlated with infant urinary cotinine and infant irritability, being also the best predictor of irritability $\left(r^{2}=0.364\right)$. Neonatal behavior can be significantly altered in a dose-dependent manner even after modest prenatal exposure to tobacco smoke. (Pediatr Res 61: 257-261, 2007)
\end{abstract}

$\mathrm{R}^{\mathrm{e}}$ ecent reports have shown that although the percentage of women smoking during pregnancy has decreased to only $10 \%$ in the United States in $2004(1,2)$, estimated smokingattributable neonatal expenditures accounted for 366 million dollars (3). Similarly, the prevalence of smoking during gestation in Italy diminished to $12 \%$ (4); in many other countries, however, prevalence rates remain high (43\% in England, 39\% in South Africa and Australia, 35\% in Denmark, 34\% in Spain, 20\% in South America, Canada and Germany, or 18\% in France) (5). This fact raises a major perinatal and pediatric health issue since tobacco smoke impairs placental function depriving the fetus from oxygen and nutrients (6). The observation of isolated transient symptoms (e.g., irritability, tremor) in newborns from heavy smoking mothers led to hypothesize the possibility of a nicotine withdrawal syndrome as a result of

Received July 7, 2006; accepted September 26, 2006

Correspondence: Simona Pichini, Ph.D., Drug Control and Evaluation Department, Istituto Superiore di Sanità, V.le Regina Elena 299, 00161 Rome, Italy; e-mail: simona.pichini@iss.it

Supported by: The Dipartimento Nazionale per le politiche antidroga della Presidenza del Consiglio dei Ministri (S.P., R.P., P.Z., Ó.G.-A.).

DOI: $10.1203 /$ pdr.0b013e31802d89eb chronic prenatal exposure to high levels of tobacco smoke $(5,7,8)$. Moreover, it has been shown that cigarette smoke, a mixture of over 4,000 compounds, can significantly affect normal intrauterine development of the fetal nervous system (9). Abnormal neurobehavioral performances that previous investigators have interestingly described in the offspring of mothers smoking during pregnancy (10) may be related. Smoking during pregnancy has been assessed by the administration of a questionnaire to the mother and by measurement of maternal salivary cotinine. However, self-reporting of smoking habits during pregnancy is known to be inaccurate due to recall bias or guilty feelings (11). Moreover, maternal salivary cotinine assay is useful to assess very recent tobacco consumption but is not useful to assess chronic intrauterine exposure to tobacco smoke in the offspring (12).

On the other hand, it has recently been shown that nicotine in different segmental of maternal hair is an adequate biomarker of chronic exposure to cigarette smoking during pregnancy, which fairly correlates with acute exposure measured by urinary cotinine concentration in the newborn (13-15).

Taking into consideration the high cost and lengthy complex procedure of hair analysis in comparison with easy, rapid, and low-cost urinary cotinine analysis, this last biomarker has a promising role to assess prenatal exposure to tobacco smoke (14).

The purpose of this study was to quantify prenatal exposure to tobacco smoke by measuring neonatal urinary cotinine and to establish a relationship between neonatal behavior evaluated by Brazelton Neonatal Behavioral Assessment Scale (BNBAS) and results of urinary cotinine testing. In fact, this instrument has been successfully used in previous studies for screening altered newborn behavior during the first days of life $(16,17)$.

\section{METHODS}

Participants. The study included 50 neonates born from mothers aged between 21 and $40 \mathrm{y}$ and admitted to the Division of Neonatology of the University of Naples "Federico II" between May 2003 and May 2004. The characteristics of newborns are summarized in Table 1. The Division of Neonatology and the whole university hospital is a smoking-free hospital since the coming into force of the 1995 legislation on tobacco banning in

Abbreviation: BNBAS, Brazelton Neonatal Behavioral Assessment Scale 
Table 1. General characteristics of the study newborns

\begin{tabular}{lcc}
\hline & $\begin{array}{c}\text { Newborns } \\
\text { from smoking } \\
\text { mothers }(n=25)\end{array}$ & $\begin{array}{c}\text { Newborns } \\
\text { from nonsmoking } \\
\text { mothers }(n=25)\end{array}$ \\
\hline Sex & & 19 \\
$\quad$ Male & 19 & 6 \\
$\quad$ Female & 6 & $38.4(37-40)$ \\
Gestational age, wks* & $38.7(37-41)$ & $8.0(7-9)$ \\
Birth weight, $\mathrm{g}^{*}$ & $3,132.4(2,550-4,140)$ & $3,307.6(2,700-4,070)$ \\
Apgar score 1* & $7.9(7-9)$ & $9.2(9-10)$ \\
Apgar score 5* & $9.0(8-10)$ & $72.0(56-72)$ \\
Postnatal age, hrs* & $72.0(56-72)$ & $7.5(4-13)$ \\
Bilirubin, mg/dL* & $6.9(2-13)$ &
\end{tabular}

* Values are expressed as mean (range).

workplaces of Public Administration and Public Companies open to free access.

Women were selected within 3 to $5 \mathrm{~d}$ after labor provided that the inclusion criteria of uncomplicated pregnancy and post-delivery good health conditions were met. Inclusion criteria for neonates were as follows: birth at term, appropriate for gestational age singletons, Apgar score $>7$ at $1 \mathrm{~min}$ and $>9$ at $5 \mathrm{~min}$, absence of any abnormality at routine physical examination, and results of routine laboratory tests, including serum bilirubin concentration within normal limits.

Exclusion criteria were major congenital malformations, hyperbilirubinemia, presence of alcohol or illicit drugs metabolites in the infant urine, and mothers consuming more than one cup of espresso coffee daily or more than a glass of caffeinated drinks other than coffee (coke, iced tea, tea, etc.), and/or more than three alcoholic drinks monthly (to avoid interference with the evaluation of neonatal behavior).

Twenty-five women whose infants fulfilled the inclusion criteria, with a history of continued active smoking of at least 5 cigarettes per day during the whole pregnancy were enrolled (Table 2). A questionnaire that included years of tobacco smoking, average number of daily smoked cigarettes and their brand, and presence of other smokers in the household was administered. From information of the questionnaire, nicotine daily intake (average number of cigarettes smoked per day multiplied by nicotine content in $\mathrm{mg}$ of each cigarette) was calculated $(11,14)$. None of the woman declared the use of tobacco products other than cigarettes or consumption of illicit substances during pregnancy. Self-reported deny of illicit drugs use was confirmed by drug testing in the first neonatal urines using a screening test (Instant-View, Alfa Scientific Designs, San Diego, CA).

An equal number of 25 nonsmoking mothers whose neonates matched the other group by gender, birth weight $( \pm 150 \mathrm{~g})$, gestational age ( $\pm 1 \mathrm{wk})$, hours of life $( \pm 5 \mathrm{~h})$, maternal age $( \pm 2.5 \mathrm{y})$, normal serum bilirubin value, and maternal and paternal educational and professional level were also enrolled in the study (Table 1). Smoking status of nonsmoking mothers was confirmed by measurement of urinary cotinine as reported in the subsequent section for newborns using a urine sample collected at the last antenatal visit and stored at $-80^{\circ} \mathrm{C}$ until analysis. Infants from both smoker and nonsmoking mothers were also matched for exposure to paternal smoke as number of smoked cigarettes (Table 2).

Table 2. Smoke-related variables of the study newborns

\begin{tabular}{lcc}
\hline & $\begin{array}{c}\text { Newborns } \\
\text { from smoking } \\
\text { mothers }(n=25)\end{array}$ & $\begin{array}{c}\text { Newborns } \\
\text { from nonsmoking } \\
\text { mothers }(n=25)\end{array}$ \\
\hline $\begin{array}{c}\text { Number of daily smoked } \\
\text { cigarettes by the mother* }\end{array}$ & $12.2(5-20)$ & 0 \\
$\begin{array}{c}\text { Maternal nicotine daily } \\
\text { intake, } m \text { m }\end{array}$ & $10.1(1.7-18.0)$ & Not applicable \\
$\begin{array}{c}\text { Number of cigarettes } \\
\text { smoked by the father }\end{array}$ & & \\
0/day & 13 & 10 \\
10-19/day & & 5 \\
$\geq 20 /$ day & 8 & 10 \\
Neonatal urinary cotinine & $170.5(2.1-1564.0)$ & $1.9(0.2-5.4)$ \\
(ng/mL)* & & \\
\hline
\end{tabular}

* Values are expressed as mean (range).
The study was approved by the local Ethical Committee, conducted according to the principles expressed in the Declaration of Helsinki and informed consent was signed by both fathers and mothers of the newborns.

Measurement of neonatal urinary cotinine. Neonatal urine samples were collected within the first $24 \mathrm{~h}$ after birth using an adhesive collection bag and stored at $-80^{\circ} \mathrm{C}$ until analysis. Immediate urine collection allowed the determination of steady-state newborn cotinine resulting from the continuous prenatal infusion of nicotine from tobacco smoke.

Urinary cotinine was measured in triplicate using a double antibody RIA according to the method of Van Vunakis et al. (18). The level of crossreactivity of cotinine antibody with other nicotine metabolites was less than $5 \%$ (19). The detectable range of measurement from the standard curve was $0.2-20 \mathrm{ng} / \mathrm{mL}$ cotinine with an interassay coefficient of variation of 6-10\%. Assays were performed blindly to the mothers' smoking status. Samples that at first determination fell outside the calibration curve were reexamined after proper dilution.

Newborns behavioral assessment. Newborns were administered the BNBAS (20). The Division of Neonatology at the University "Federico II" is in fact a recognized Brazelton Center since 1996 associated to the Brazelton Center for Infants and Parents of the Harvard University.

All examinations took place in a quiet examination room under soft lighting and temperature conditions $\left(22-27^{\circ} \mathrm{C}\right)$. Infants were examined at $56-72 \mathrm{~h}$ of life to allow infant's adaptation to extrauterine life by a certified examiner who was blind to whether tobacco smoke exposure was positive or negative.

The BNBAS (20) includes 28 behavioral items each scored on a 9-point scale and 18 reflex items each scored on a 3-point scale. Clusters of items can be analyzed, such as habituation, orientation, motor performance, ranges of state, autonomic regulation, and reflexes. For analysis, all scores were converted from curvilinear to linear as indicated in BNBAS, so that a high score indicates a high energy level response and good auto-regulation to disturbance stimuli, whereas a low score indicates a low auto-regulation to disturbance stimuli response.

Statistical analysis. Since cotinine values did not follow a normal distribution, cotinine concentrations were log-transformed. Neonates from smoker and nonsmoking mothers were compared in their performance on each of BNBAS items using the nonparametric Wilcoxon test for paired data. Nonparametric Spearman correlation coefficient was used to assess the relationship among independent variables within the sample (urinary cotinine concentration, number of daily smoked cigarettes, gestational age, birth weight) and the score on each of BNBAS item. Linear regression analysis was used to assess main predictors of variance. The Statistical Package for Social Sciences (SPSS), version 11.5 for Windows was used tp analyze the data. Statistical significance was set at $p<0.05$.

\section{RESULTS}

As established at the beginning of the study, newborns characteristics did not differ between the two study groups, apart from the in utero exposure to maternal smoking (Tables 1 and 2). In this sense, since some smoking mothers declared exposure to their partner smoke, nonsmokers mothers were chosen with similar exposure (measured as number of daily cigarettes smoked by the partner).

The average number of daily smoked cigarettes by smoking mothers during pregnancy was 12.2 with a mean nicotine daily intake of $10.1 \mathrm{mg}$. Neonatal urinary cotinine was significantly associated with maternal daily nicotine intake $(\mathrm{r}=0.618, p<$ 0.005 , Fig. 1), but not with the number of daily cigarettes smoked by the father. Some infants from nonsmoking mothers showed a measurable value of urinary cotinine. Interestingly, in these cases paternal smoking ( as number of daily cigarettes) was significantly related to newborn urinary cotinine $(\mathrm{r}=0.829, p<0.001$, Fig. 2).

Neonates of mothers who had smoked during their pregnancy showed significantly poorer performances in several items of BNBAS when compared with neonates from nonsmoking mothers (Table 3). Indeed, scores for the majority of 


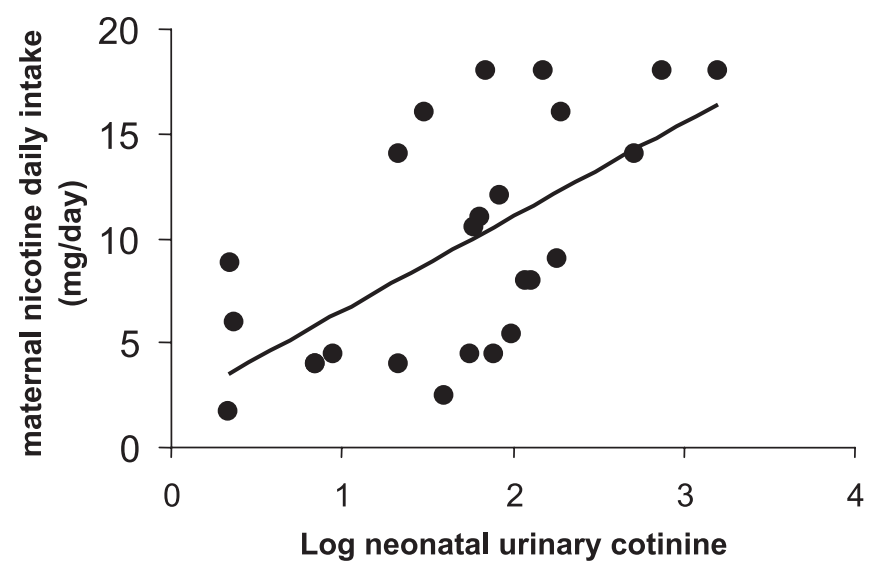

Figure 1. Log-transformed cotinine values in urine of neonates $(\mathrm{ng} / \mathrm{mL})$ from smoking mothers as a function of maternal nicotine daily intake $(\mathrm{mg} / \mathrm{d})$.

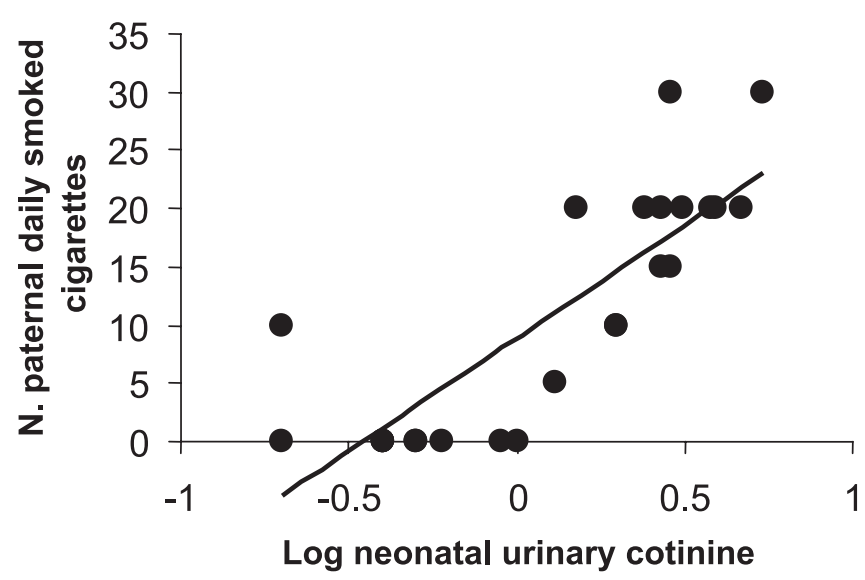

Figure 2. Log-transformed cotinine values in urine of neonates $(\mathrm{ng} / \mathrm{mL})$ from nonsmoking mothers as a function of number of paternal daily smoked cigarettes.

social-interactive items, defense, irritability, and tremors were lower in newborns in utero exposed to maternal smoke.

In addition, neonates from both smoker and nonsmokers mothers with a measurable cotinine value $(\geq 0.20 \mathrm{ng} / \mathrm{mL})$, a significant negative correlation was observed between the infant irritability score (where a higher value corresponds to a lower irritability and to a better auto-regulation) and his/her urinary cotinine $(r=-0.698, p<0.001)$. In infants from smoking mothers, irritability was inversely correlated with maternal nicotine daily intake $(r=-0.547, p=0.008)$. In the multiple regression analysis, urinary cotinine was the single best variance predictor for irritability $\left(r^{2}=0.727\right)$. The neonate's quality of attention score was inversely correlated with urinary cotinine $(r=-0.562, p<0.001)$, maternal nicotine daily intake in newborns from smoking mothers $(r=-0.437$, $p<0.05)$, and irritability $(r=-0.585, p<0.001)$. On the other hand, multiple regression analysis showed that urinary cotinine was the best variance predictor for poor neonatal quality of attention $\left(r^{2}=0.266\right)$.

In the socio-interactive area, there was a negative correlation between inanimate auditive items and urinary cotinine $(r=-0.487, p<0.001)$, irritability $(r=0.437, p<0.001)$ and maternal nicotine daily intake in newborns from smoking mothers $(r=-0.459, p<0.005)$. Urinary cotinine was the best variance predictor for poor auditory performance of the neonate $\left(r^{2}=0.216\right)$. Exploring neurobehavioral items that estimate the states regulation, a significant negative correlation between consolability and urinary cotinine was found $(r=-0.287, p<0.005)$. Tremors were also significantly correlated to urinary cotinine $(r=-0.451, p<0.001)$ and with maternal nicotine daily intake in newborns from smoking mothers $(r=-0.477, p<0.001)$. Urinary cotinine was the best variance predictor of tremors $\left(r^{2}=0.228, p<0.001\right)$. Unexpectedly, in infants from nonsmoking mothers, paternal smoking was significantly related to irritability $(r=-0.616$, $p=0.001)$. Regression analysis showed that paternal smoking was the best predictor of infant irritability among newborns of nonsmoking mothers $\left(r^{2}=0.364\right)$. Conversely, in newborns from smoking mothers, paternal smoking was not associated with any altered behavior measured by BNBAS.

\section{DISCUSSION}

This study shows that maternal smoking during the entire pregnancy is associated with irritability in the newborn infant, which in turn is less interactive with the environment. Newborn behavior was evaluated using the BNBAS, already applied in previous investigations regarding tobacco smoke (2124). However, it is somewhat surprising that some of these studies did not find any significant behavioral difference related to maternal tobacco use during pregnancy $(21,22)$. However, these older studies often examined tobacco in the context of other factors such as illicit substance abuse or obstetric complications (25).

This study was designed to pinpoint specific tobacco effects excluding most likely confounders: the two groups of newborns were carefully matched and assessed during the perinatal period in an appropriate way; infant exposure to cigarette smoke was measured directly by neonatal urinary cotinine; therefore, due to the methodologic rigurosity of the study, differences found between the study groups are relevant and outstanding.

The present findings are in agreement with those recently reported by Law et al. (10). These authors using a behavioral research tool similar to BNBAS, showed a relationship between neonatal impaired neurobehavior and maternal tobacco use in pregnancy. An important methodologic difference between the study of Law et al. (10) and the present study is the use of maternal salivary cotinine to assess maternal smoking during pregnancy as compared with quantification of the same nicotine metabolite in infant urine, which accounts for the fetal exposure to smoke. However, either maternal or newborn biomarkers reflected exposure to tobacco smoke at the end of the pregnancy underestimating eventual smoking consumption or exposure earlier in pregnancy. Indeed, this period is known to be relevant with regard to a number of outcomes. Hence, a limitation of studies using a biomarker of recent exposure is that a certain percentage of women could have quitted tobacco smoke during pregnancy (usually first trimester) and at delivery declared to be nonsmokers. Nonetheless, if mothers who gave up smoking produced any bias in the 
Table 3. Scores on behavioral items of the BNBAS by newborns from smoker and non smoking mothers during pregnancy

\begin{tabular}{|c|c|c|c|}
\hline & $\begin{array}{c}\text { Newborns } \\
\text { from smoking } \\
\text { mothers }(n=25)\end{array}$ & $\begin{array}{c}\text { Newborns } \\
\text { from nonsmoking } \\
\text { mothers }(n=25)\end{array}$ & $p$ \\
\hline \multicolumn{4}{|l|}{ Habituation } \\
\hline Rattle & $6(3.9-6.2)$ & $6(3.7-6.7)$ & 1.00 \\
\hline Bell & $5(4.4-6.1)$ & $6.5(3.7-8.2)$ & 0.655 \\
\hline Pinprick & $5(4.4-5.3)$ & $5.5(3.7-6.7)$ & 1.00 \\
\hline Animate auditory & $5(4.1-6.9)$ & $7(4.7-7.2)$ & 0.001 \\
\hline Animate visual and auditory & $6(4.4-7.0)$ & $7(4.9-8.0)$ & 0.001 \\
\hline Inanimate visual & $5(4.1-6.9)$ & $6(3.9-7.0)$ & 0.011 \\
\hline Inanimate auditory & $5(4.9-6.8)$ & $7(4.9-8.0)$ & 0.001 \\
\hline Inanimate visual and auditory & $5(4.9-7.2)$ & $7(4.7-7.7)$ & 0.015 \\
\hline Alertness & $4(4.1-5.2)$ & $6(3.9-5.5)$ & 0.006 \\
\hline Defense & $5(4.3-5.8)$ & $6(4.3-9.1)$ & 0.003 \\
\hline Activity & $5(4.1-5.2)$ & $5(3.9-5.5)$ & 0.025 \\
\hline \multicolumn{4}{|l|}{ State organization } \\
\hline Peak of excitement & $4(3.2-4.2)$ & $4(3.4-5.0)$ & 0.011 \\
\hline Rapidity of buildup & $4(3.6-4.9)$ & $5(2.7-7.2)$ & 0.544 \\
\hline Irritability & $5(4.7-6.1)$ & $6(4.5-6.4)$ & 0.001 \\
\hline Liability of state & $3(2.4-3.3)$ & $3(1.9-3.5)$ & 0.250 \\
\hline \multicolumn{4}{|l|}{ State regulation } \\
\hline Cuddliness & $6(5.5-6.7)$ & $6(5.5-7.4)$ & 0.245 \\
\hline Consolability & $5(4.8-6.7)$ & $6(3.7-7.7)$ & 0.013 \\
\hline Self-quieting & $6(5.0-6.6)$ & $6(2.4-7.5)$ & 0.327 \\
\hline Hand-to-mouth & $1(1.8-4.1)$ & $2(0.2-4.2)$ & 0.773 \\
\hline
\end{tabular}

Data are expressed as median and $95 \%$ confidence interval.

association between cotinine levels and the eventual effects in infants, this bias would have been conservative.

Differently from Law et al., which administered the Network Neurobehavioral Scale within $48 \mathrm{~h}$ after birth; in our study newborns were tested between 56 and $72 \mathrm{~h}$ of life. This was made to be out of the life period (usually within the first $48 \mathrm{~h}$ after birth) in which an eventual neonatal nicotine withdrawal syndrome (or only symptoms) could have occurred to newborns from heavy smokers affecting the results of BNBAS $(5,7)$.

The accurate assessment of fetal exposure to smoking through the objective measure of a biomarker allowed the first and definitive demonstration of a direct correlation between neonatal behavioral alterations and different levels of prenatal exposure to smoke. Our data further support the hypothesis that maternally derived nicotine and cigarette smoke compounds act directly on the developing fetal nervous system (26).

A difference between newborns prenatally exposed to active maternal smoke and those exposed to passive smoke has to be pointed out. When the newborn is directly exposed to maternal tobacco smoke (calculated in fact as maternal daily nicotine intake) through feto-placental circulation, second hand paternal smoking (calculated as the number of smoked cigarettes) seems not to show any additive effect to the observed altered behavior. In contrast, whatever the precise mechanism of action of nicotine and other compounds on neural cells, in the absence of active maternal exposure, paternal smoking seems to have an effect although to a lesser extent. In fact, in newborns from nonsmoking mothers, paternal smoke significantly correlated with both neonatal urinary cotinine and irritability, although scores were significantly higher than those in infants from the active smoking groups.

\section{CONCLUSIONS}

Prenatal exposure to active or passive maternal tobacco smoke is significantly associated with neonatal behavioral alterations. Our data indicate a continuum rather than a threshold phenomenon. We believe that these observations shed further light on the interactions between nicotine and tobacco smoke compounds and the developing nervous system and may be relevant to health providers involved in educating smoking mothers and fathers to quit smoking as responsible parenthood.

Acknowledgments. The authors thank the mothers and the nursing staff of the Division of Neonatology of the University 
of Naples "Federico II" at for their efficient help, and Dr. Marta Pulido for manuscript editing.

\section{REFERENCES}

1. Hoyert DL, Mathews TJ, Menacker F, Strobino DM, Guyer B 2006 Annual summary of vital statistics: 2004. Pediatrics 117:168-183

2. Lester BM, Tronick EZ, LaGasse L, Seifer R, Bauer CR, Shankaran S, Bada HS, Wright LL, Smeriglio VL, Lu J, Finnegan LP, Maza PL 2002 The maternal lifestyle study: effects of substance exposure during pregnancy on neurodevelopmental outcome in 1-month-old infants. Pediatrics 110:1182-1192

3. Centers for Disease Control and Prevention 2004 Smoking during pregnancy United States - 1990-2002 MMWR Morb Mortal Wkly Rep 53:911-915

4. Chatenoud L, Chiaffarino F, Parazzini F, Benzi G, La Vecchia C 1999 Prevalence of smoking among pregnant women is lower in Italy than England. BMJ 318:1012

5. Pichini S, García-Algar O 2006 In utero exposure to smoking and newborn neurobehavior: how to assess neonatal withdrawal syndrome? Ther Drug Monit 28:288290

6. Bush PG, Mayhew TM, Abramovich DR 2000 Maternal cigarette smoking and oxygen diffusion across the placenta. Placenta 21:824-833

7. Garcia-Algar O, Puig C, Mendez C, Vall O, Pacifici R, Pichini S 2001 Neonatal nicotine withdrawal syndrome. J Epidemiol Community Health 55:687-688

8. Godding V, Bonnier C, Fiasse L, Michel M, Longueville E, Lebecque P, Robert A, Galanti L 2004 Does in utero exposure to heavy maternal smoking induce nicotine withdrawal symptoms in neonates? Pediatr Res 55:645-651

9. Andres RL, Day MC 2000 Perinatal complications associated with maternal tobacco use. Semin Neonatol 5:231-241

10. Law KL, Stroud LR, LaGasse LL, Niaura R, Liu J, Lester BM 2003 Smoking during pregnancy and newborn neurobehavior. Pediatrics 111:1318-1323

11. Pichini S, Basagaña X, Pacifici R, Garcia O, Puig C, Vall O, Harris J, Zuccaro P, Segura J, Sunyer J 2000 Cord serum cotinine as a biomarker of foetal exposure to cigarette smoke at the end of pregnancy. Environ Health Perspect 108:1079-1083

12. Garcia-Algar O, Puig C, Vall O, Pacifici R, Pichini S 2004 Effects of maternal smoking during pregnancy on newborn neurobehavior: neonatal nicotine withdrawal syndrome. Pediatrics 113:623-624
13. Eliopoulos C, Klein J, Phan MK, Knie B, Greenwald M, Chitayat D, Koren G 1994 Hair concentrations of nicotine and cotinine in women and their newborn infants. JAMA 271:621-623

14. Pichini S, Garcia-Algar Ó, Muñoz L, Vall O, Pacifici R, Figueroa C, Pascual JA, Diaz D, Sunyer J 2003 Assessment of chronic exposure to cigarette smoke and its change during pregnancy by segmental analysis of maternal hair nicotine. J Expo Anal Environ Epidemiol 13:144-151

15. Klein J, Blanchette P, Koren G 2004 Assessing nicotine metabolism in pregnancy-a novel approach using hair analysis. Forensic Sci Int 145:191-194

16. Paludetto R, Mansi G, Raimondi F, Romano A, Crivaro V, Bussi M, D’Ambrosio G 2002 Moderate hyperbilirubinemia induces a transient alteration of neonatal behavior. Pediatrics 110:E50

17. Mansi G, De Maio C, Araimo G, Rotta I, Crivaro V, Sarno M, Raimondi F, Paludetto R 2003 Safe" hyperbilirubinemia is associated with altered neonatal behavior. Biol Neonate 83:19-21

18. Van Vunakis H, Gjika HB, Langone J 1993 Radioimmunoassays for nicotine and cotinine. IARC Sci Publ 109:293-299

19. Zuccaro P, Altieri I, Rosa M, Pellegrini M, Pacifici R 1997 Interference of nicotine metabolites in cotinine determination by RIA. Clin Chem 43:180-181

20. Brazelton TB, Nugent JK 1995 Neonatal Behavioral Assessment Scale. $3^{\text {rd }}$ edition, Cambridge University Press, Cambridge

21. Jacobson SW, Fein GG, Jacobson JL, Schwartz PM, Dowler JK 1984 Neonatal correlates of prenatal exposure to smoking, caffeine and alcohol. Infant Behav Dev 7:253-265

22. Richardson GA, Day NL, Taylor PM 1989 The effect of prenatal alcohol, marijuana, and tobacco exposure on neonatal behavior. Infant Behav Dev 12:199-209

23. Saxton DW 1978 The behavior of infants whose mothers smoke in pregnancy. Early Hum Dev 2:363-369

24. Oyemade UJ, Cole OJ, Johnson AA, Knight EM, Westney OE, Laryea H, Hill G, Cannon E, Fomufod A, Westney LS, Jones S, Edwards CH 1994 Prenatal substance abuse and pregnancy outcomes among African American women. J Nutr 124:994S999S

25. Fried PA, Makin JE 1987 Neonatal behavioral correlates of prenatal exposure to marijuana, cigarettes and alcohol in a low risk population. Neurotoxicol Teratol 9:1-7

26. Lambers DS 1996 The maternal and foetal physiologic effects of nicotine. Semin Perinatol 20:115-126 